\title{
Evaluation of the measurement properties of the Manchester foot pain and disability index
}

\author{
Babette C van der Zwaard ${ }^{1 *}$, Caroline B Terwee ${ }^{2}$, Edward Roddy ${ }^{3}$, Berend Terluin ${ }^{1}$, Henriette E van der Horst ${ }^{1}$ \\ and Petra JM Elders ${ }^{1}$
}

\begin{abstract}
Background: The Manchester Foot Pain and Disability Index (MFPDI, 19 items) was developed to measure functional limitations, pain and appearance for patients with foot pain and is frequently used in both observational studies and randomised controlled trials. A Dutch version of the MFPDI was developed. The aims of this study were to evaluate all the measurement properties for the Dutch version of the MFPDI and to evaluate comparability to the original version.
\end{abstract}

Method: The MFPDI was translated into Dutch using a forward/backward translation process. The dimensionality was evaluated using exploratory and confirmatory factor analysis. Measurement properties were evaluated per subscale according to the COSMIN taxonomy consisting of: reliability (internal consistency, test-retest reliability and measurement error), validity (structural validity, content validity and cross-cultural validity comparing the Dutch version to the English version) responsiveness and interpretation.

Results: The questionnaire consists of three scales, measuring foot function, foot pain and perception. The reliability of the foot function scale is acceptable (Cronbach's a $>0.7, I C C=0.7, S E M=2.2$ on 0-18 scale). The construct validity of the function and pain scale was confirmed and only the pain scale contains one item with differential item functioning (DIF). The responsiveness of the function and pain scale is moderate when compared to anchor questions.

Conclusion: Results using the Dutch MFPDI version can be compared to results using the original version. The foot function sub-scale (items 1-9) is a reliable and valid sub-scale. This study indicates that the use of the MFPDI as a longitudinal instrument might be problematic for measuring change in musculoskeletal foot pain due to moderate responsiveness.

\section{Background}

Foot pain is common in older people and is associated with functional limitations in foot related activities; prevalences between 14.9 and $41.9 \%$ have been reported in people over 50 years [1-6]. The Manchester Foot Pain and Disability Index (MFPDI) is a 19 item tool developed to measure foot pain and foot related function in patients with foot pain [7]. It intends to measure 3 constructs: functional limitation, pain and personal appearance [7]. Statements relating to the 3 constructs can be answered in terms of frequencies: 'none of the time', 'on

\footnotetext{
*Correspondence: b.vanderzwaard@vumc.nl

${ }^{1} \mathrm{EMGO}+$ Institute for health and care research, Department of general practice and elderly care medicine, VU University Medical Centre, Amsterdam, The Netherlands

Full list of author information is available at the end of the article
}

some days' and 'on most/every day(s)'. Previous studies have evaluated some of the measurement properties of the questionnaire. Internal consistency (IC) is the most evaluated property [7-12] although some studies evaluated it over the entire questionnaire instead of over the three constructs (i.e. sub-scales) $[7,9,10]$. The studies that did evaluate each sub-scale separately have found the scales to be internal consistent $[8,12]$. Test-retest reliability has been analysed by Roddy et al. [12] and found to be moderate for the pain and the appearance scale and both moderate and acceptable for the functional limitations scale depending on the inclusion criterion. Construct validity has been described in previous studies although the amount of hypotheses tested was small in one study [7] and no hypotheses were stated a priori in another [10]. The characteristics of the items in the questionnaire have

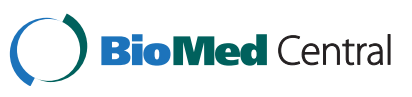


been thoroughly examined using item response theory testing (IRT). The MFPDI consists of items that allow severe cases to be distinguished from the less severe cases $[8,11]$.

The MFPDI is not merely a descriptive tool (e.g. in cross-sectional studies) but it is also used as a tool to measure change over time as a result of an intervention [13-15]. When interpreting change scores in a randomised controlled trial (RCT) or another longitudinal study, it is vital to have knowledge about measurement properties like measurement error, responsiveness and interpretation values like minimal important change (MIC) and smallest detectable change (SDC). Currently these properties have not been assessed yet. For the purpose of a Dutch study on forefoot pain in people 50 years of age or older the MFPDI had to be translated into Dutch [15]. The aims of the current study are, firstly, to create a Dutch version of the MFPDI. Secondly, to evaluate measurement properties based on the Classical Test Theory (CTT), including a cross-cultural validation of the Manchester Foot Pain and Disability Index using the Dutch translated version.

\section{Method}

This study describes an evaluation of measurement properties of the MFPDI starting with the translation of the questionnaire into Dutch. The Medical Ethics Committee of the VU University Medical Centre in Amsterdam has approved the design of this study (No. 2009/267).

\section{Translation}

A forward-backward method of translation was used to obtain a Dutch version of the MFPDI [16]. Two translators; a general practitioner and a physical education teacher, both with additional experience with English, translated the original version into Dutch. During the consensus meeting with the two translators and guided by $\mathrm{PE}$ and BvdZ, a consented Dutch version was established. This version was then translated back into English by two native speakers; a UK scientific researcher and a UK physician assistant. Differences between the original and the translated version were discussed by BvdZ and PE and the Dutch version was accordingly adapted. The Dutch version was then tested by 10 participants, who were asked about intelligibility and completeness of the list. Concerns identified regarding intelligibility and completeness were discussed between BvdZ and $\mathrm{PE}$ and adapted if required.

\section{Participants}

As part of an RCT that compares treatment of forefoot pain by means of podiatric care or shoe advice, participants aged 50 years and over with non traumatic forefoot pain that lead to functional limitations were recruited [15]. Exclusion criteria were: the presence of diabetic neuropathy, non musculoskeletal foot pain (e.g. warts) or pain caused by rheumatoid arthritis. Participants had to be able to walk un-assisted for 7 metres. These participants completed the MFPDI on multiple occasions during the trial as part of self administered questionnaires. The MFPDI was used as a screening tool; participants had to score at least one item on the MFPDI as occurring 'on most/every day(s)' to be considered limited functionally and thus eligible for the trial.

\section{Procedure and outcome measures}

Preceding inclusion the MFPDI was used as a screening tool (NL Ts). One to three weeks later the participants were included in the trial and completed a comprehensive questionnaire with the below mentioned comparator instruments and the MFPDI as a baseline measurement (NL T0). Since all participants had at least 3 months of foot pain and were considered to have limited functionality indicating a stable state no additional measures were taken to assess possible changes between baseline and screening. Three months after baseline a similar questionnaire was completed again (NL T3). The lowest response in the MFPDI was marked as 0 and the highest response as 2. The COSMIN taxonomy was utilized to evaluate every measurement property of the MFPDI questionnaire $[17,18]$.

As comparator instruments to the MFPDI several other questionnaires were completed: the Foot Function Index-5 pt [19] (FFI-5 pt), SF12 ${ }^{\circ}$ and an 11 point pain intensity numeric rating scale (NRS where $0=$ no pain and $10=$ worst possible pain). The FFI-5 pt is a questionnaire on foot function, consisting of two subscales: foot pain and foot related activities, consisting of respectively 7 and 8 items. The original FFI is more extensive (23 items), has response options using visual analogue scales (VAS) and was developed for people with rheumatoid arthritis. The FFI-5 pt has been validated for use in the elderly with non rheumatic foot problems, has 5 response options (ranging from "no pain" to "intense pain" and from "no difficulty" to "impossible") and has already been translated into Dutch [19]. In addition to the comparator instruments and the MFPDI, two global perceived effect (GPE) questions on foot pain and foot related disability were added to the NL T3 questionnaire: "How would you judge the pain in your foot now, compared to three months ago?" and "How would you judge the performance of foot related activities now, compared to three months ago?". These GPE questions could be answered with: "much worse, worse, no change, better or much better".

\section{UK sample for cross-cultural validation}

For the purpose of assessing cross-cultural validity, a sub-sample of data was obtained from two phases of the North Staffordshire Osteoarthritis Project (NorStOP) 
[20-22]. The sampling frame consisted of all adults aged 50 years and over registered with six general practices in North Staffordshire, UK. Briefly, NorStOP consisted of a two-stage cross-sectional questionnaire. Stage 1 consisted of a postal Health Survey questionnaire. Respondents to this questionnaire who reported experiencing foot pain in the last 12 months were sent a Regional Pain Survey questionnaire which contained the MFPDI. Respondents were also asked to provide consent for review of their medical records.

Criteria for inclusion in the sub-sample for this analysis were: having foot pain in the last 12 months, reporting at least 2 items on the MFPDI occurring on "some days" or "most/every day(s)", and both providing consent to medical record review and consulting their GP with musculoskeletal foot problems in the 18 months prior to the baseline Health Survey. Participants who had diabetes mellitus (self-report in Health Survey questionnaire) or had consulted their GP for rheumatoid arthritis in the 18 months prior to the baseline Health Survey were excluded.

\section{Statistical analyses}

First, the dimensionality of the Dutch version of the MFPDI was investigated using an exploratory factor analysis (EFA). A confirmatory factor analysis (CFA) was used to evaluate the fit of the 3 construct conceptual model $[7,11,12]$ on the Dutch data. CFA was also used to test both the 3 construct conceptual model and the EFA findings on the UK data. The last two items of the MFPDI ("I am unable to carry out my previous work" and "I no longer do all my previous activities") were not applicable for a large number of participants (39\%) and were thus not used for either analyses. Model fit was evaluated by comparing Root Mean Square Error of Approximation (RMSEA), Comparative Fit Index (CFI) and Tucker-Lewis fit Index (TLI) from the two different models. RMSEA $\leq 0.06$ indicated good model fit and for CFI and TLI a cut off value of 0.95 was chosen $[23,24]$.

\section{Reliability}

Internal consistency (IC) IC was evaluated per sub-scale of the NL T0 data using Cronbach's $\alpha$. An outcome between 0.7-0.95 was considered acceptable [25].

\section{Test-retest reliability}

To evaluate test-retest reliability, the intra class correlation $\left(\mathrm{ICC}_{\text {agreement }}\right.$ ) was calculated comparing the NL Ts to the NL T0 data. Variance components were estimated using the VARCOMP tool in SPSS. The $\mathrm{ICC}_{\text {agreement }}$ was calculated by dividing the variance between patients by the sum of the variance between patients $\left(\sigma_{p}^{2}\right)$, the variance due to systematic differences between observations $\left(\sigma_{0}^{2}\right)$ and the residual variance $\left(\sigma_{\text {residual }}^{2}\right)$ (equation 1$)$ [26]. An ICC of 0.7 or higher was deemed acceptable [25].

$$
I C C_{\text {agreement }}=\frac{\sigma_{p}^{2}}{\sigma_{p}^{2}+\sigma_{o}^{2}+\sigma_{\text {residual }}^{2}}
$$

\section{Measurement error}

The standard error of measurement $\left(\mathrm{SEM}_{\text {agreement }}\right)$ was calculated using the same variance components used for the $\mathrm{ICC}_{\text {agreement }}$ calculation (equation 2) [26], comparing the NL T0 with the NL Ts data.

$$
S E M_{\text {agreement }}=\sqrt{\left(\sigma_{o}^{2}+\sigma_{\text {residual }}^{2}\right)}
$$

\section{Validity}

Construct validity In order to evaluate construct validity the 'hypotheses testing' method was chosen in absence of a gold standard [27]. Hypotheses were formulated based on two general assumptions [27]. First, correlations between MFPDI subscales and (subscales of) similar questionnaires should be $>0.50$. Second, correlations between MFPDI subscales and dissimilar questionnaires or subscales should be lower. The following seven a priori defined hypotheses stating expected correlations between sub-scales of the MFPDI and the sub-scales of the FFI5pts, SF-12 and NRS within the NL T0 data were tested using Pearson correlations:

1. The score of the MFPDI- function items (MFPDI-f) correlates with the score of the FFI- 5 pts function items (FFI-f) with $\mathrm{R}>0.5$;

2. The score of the MFPDI-f correlates with the score of the SF12 physical function items (SF-12phys) with $\mathrm{R}>0.3$;

3. $\mathrm{R}$ hypotheses $1>\mathrm{R}$ hypotheses 2 ;

4. The score of the MFPDI- pain items (MFPDI-p) correlates with the score of the FFI- 5pts pain items (FFI-p) with $\mathrm{R}>0.5$;

5. The score of the MFPDI-p correlates with the score of the Pain Numeric Rating Scale (NRS-p) with $R>0.5$;

6. $\mathrm{R}$ of the MFPDI-f - SF-12 phys $>\mathrm{R}$ of the MFPDI- $\mathrm{f}$ - the SF12 mental function items (SF-12ment);

7. $\mathrm{R}$ of the MFPDI-f - SF-12 phys $>\mathrm{R}$ of the MFPDI-p - SF-12 phys.

The construct was deemed valid if 5 out of 7 hypotheses were confirmed [25].

\section{Cross-cultural validity}

Differential Item Functioning Analyses (DIF analyses) between NL T0 and UK NorStOP data using ordinal 
logistic regression based on IRT was used to test crosscultural validity. An IRT based model does not use observed sub-scale scores but incorporates item difficulty with sub-scale score providing an estimated score of the latent trait (e.g. foot function, foot related pain); theta. A negative theta implied a low dysfunction, a positive theta more foot dysfunction. The responses to each item (dependent variables) by Dutch and UK participants with similar foot dysfunction were compared to evaluate if country of origin (independent variable) significantly affects the response [28]. An item displays DIF when patients with the same estimated theta on the sub-scale do not have the same probability of endorsing that item. There are two kinds of possible DIF: uniform and nonuniform. Uniform DIF means that in one population an item is endorsed less (or more) often at all values of the construct, compared to the other population. Nonuniform DIF means that in one population an item is endorsed less (or more) often at some values of the construct, but more (or less) often at other values of the construct, compared to the other population. Nonuniform and uniform DIF are comparable to respectively effect modification and confounding in epidemiology. A significant effect was present if more then $2 \%$ of the variance $\left(R^{2}\right)$ was due to country of origin. A uni-dimensional construct could only be tested if the sub-scale consists of at least five items, sub-scales with less items were not analysed [29].

\section{Responsiveness}

In order to evaluate if the MFPDI was responsive to change a construct approach was chosen by absence of a gold standard. Change scores between the NL T0 and NL T3 data were calculated. The following seven hypotheses comparing the change scores of the functional limitation and pain sub-scales of the MFPDI to the change scores of FFI-5pt, SF12 and the NRS and to the GPE questions using Pearsons correlation $(\mathrm{p}<0.05)$ :

1. The change score of the MFPDI- function items (MFPDI-f) correlates with the change score of the FFI- 5pts function items (FFI-f) with $R>0.5$;

2. The change score of the MFPDI-f correlates with the change score of the SF12 physical function items (SF-12 phys) with $\mathrm{R}>0.3$;

3. The change score of the MFPDI-f correlates with the GPE-function question with $\mathrm{R}>0.5$;

4. R hypotheses $1>\mathrm{R}$ hypotheses 2 ;

5. The change score of the MFPDI- pain items (MFPDI-p) correlates with the change score of the FFI- 5pts pain items (FFI-p) with $\mathrm{R}>0.5$;

6. The change score of the MFPDI-p correlates with the change score of the Pain Numeric Rating Scale (NRS-p) with R > 0.5;
7. The change score of the MFPDI-p correlates with the GPE-pain question with $\mathrm{R}>0.5$;

The questionnaire was deemed responsive when 5 out of 7 hypotheses were confirmed [25].

\section{Interpretability}

A MIC was established using the visual anchor-based MIC distribution method [30]. GPE scores were used to calculate sensitivity and specificity at each possible cutoff point for the changes in MFPDI scores between NL T0 and NL T3; the MIC is the change score for which the sum of proportion of misclassification is smallest (i.e. (1-sensitivity) + (1-specificity)). A MIC was only calculated if responsiveness hypotheses three and seven were confirmed [30].

The SDC was calculated using the SEM $_{\text {agreement }}$ (equation 3)

$$
S D C=1.96 * \sqrt{2} * S E M_{\text {agreement }}
$$

The calculated MIC has to be bigger than the SDC in order for important change to be distinguishable from measurement error in individual patients.

Lastly the presence of a floor or ceiling effect was evaluated within the NL T0 data. If $15 \%$ of the candidates obtained the minimum or maximum sub-scale score a respectively floor or ceiling effect was present [27].

\section{Software}

CFA and EFA were established using $\mathrm{M}+$ version 6.11 . The 'lordif' package in R was used for analysis of crosscultural validity [28]. SPSS (IBM SPSS Statistics for Windows, Version 20.0. Armonk, NY: IBM Corp.) was used to evaluate the remaining measurement properties. All measurement properties were evaluated for every uni-dimensional sub-scale derived from the previous mentioned EFA and CFA.

\section{Results}

\section{Translation}

Comparison of Dutch version of the questionnaire to the original English version demonstrated four differences that needed attention. The original item one states "I avoid walking outside at all", the "at all" was missing in the Dutch and back translated version, and therefore 'geheel' was added to the statement. Item 2 ("I avoid walking long distances") was re-translated to: "I avoid walking longer distances" ("Ik vermijd het lopen over langere afstand"). After back translation this was changed into: "Ik vermijd het lopen over lange afstanden" which back translates better into the original version. The original item 10 states: "I still do everything but with more pain or discomfort". After back translation "still" was missing; "nog steeds" was 
added to the Dutch version. And finally questions 12 and 13: there is no literal Dutch word for "self-conscious"; "negatief bewust" was our first choice which means: "negatively aware". After discussion during the back translation we opted for: "verlegen" ("shy") which in Dutch language is closer to the original although it will be impossible to get an exact translation. After pilot testing $(\mathrm{n}=10)$ no more changes where made to the Dutch version of the MFPDI.

\section{Participants}

The characteristics of the participants at screening, baseline and three months for the Dutch (NL Ts, NL T0 and NL T3) and the UK (UK NOrStOP; $\mathrm{n}=370$ ) participants are presented in Table 1 . The UK participants scored significantly higher $(\mathrm{p}<0.001)$ compared to the Dutch participants on the severity of foot related disability and foot pain (higher score indicates more disability or pain). The Dutch participants scored significantly lower on both the physical and mental components of the SF12 questionnaire (lower score indicates lower well-being). Baseline characteristics of participants remaining in the NL T3 $(n=178)$ and NL Ts $(n=195)$ do not differ significantly from those in the NL T0 $(n=205)$. Ten NL Ts were not used since the screening form was completed on the same or previous day as completion of NL T0.

\section{Missing values}

The highest percentage of missing values per item of the MFPDI is $2.4 \%$ (items 2, 13, 16). Combining the UK and Dutch data for the DIF analyses for the cross cultural validity item 3 had the highest percentage of missing values: $2.8 \%$. One participant in the UK data had more than $50 \%$ missing values and this participant was excluded from further analyses.

\section{Factor analysis}

Using EFA three sub-scales were found in NL T0 data: A foot function scale (items 1-9), a pain scale (items 10,
14-17) and a perception scale (items 11-13). Our factor structure differed from the previously reported factor structure $[7,11,12]$ by the location of item 11 ('I get irritable when my feet hurt'). In our analysis it was included in the perception scale whereas in previous studies it was included in the functional limitations scale. Our factor structure demonstrated the best fit in both data sets (Table 2).

\section{Reliability}

Internal consistency The functional limitation sub-scale was deemed to be internal consistent (Cronbach's $\alpha>0.7$ ). The internal consistency of the pain and perception sub-scales were moderate (Table 3).

Test-retest reliability None of the ICC values reached the generally accepted limit of 0.7 although the ICC for the foot function sub-scale was 0.69 (Table 3).

Measurement error The SEM of the perception subscale was large ( $36 \%$ of the maximum scale score). Both the foot function and the foot pain scale contained a smaller SEM; respectively $12 \%$ and $16 \%$ of the maximum scale score.

\section{Validity}

Construct validity All a priori stated hypotheses about correlations of the MFPDI function and pain scales to the FFI-5pt, SF12 and NRS were confirmed (Table 2).

Cross cultural validity Due to the limited amount of items $(<5)$ in the perception sub-scale, DIF analysis was not performed on this sub-scale. DIF analysis on the foot function sub-scale showed that there was no DIF between the UK and a Dutch population (Table 2). Item 17 in the foot pain sub-scale ("I get shooting pain in my feet") showed uniform DIF. Having a similar level of foot pain (theta), the Dutch population has a higher probability of

Table 1 Participant characteristics and item responses

\begin{tabular}{|c|c|c|c|c|c|}
\hline & & NL Ts $(n=195)$ & NL TO $(n=205)$ & NL T3 $(n=169)$ & UK NOrStOP $(n=370)$ \\
\hline Age: mean (SD) & & - & $64.1(9.4)$ & - & $65.3(9.4)$ \\
\hline Gender (\% Female) & & - & $77.6 \%$ & - & *63\% \\
\hline \multirow{3}{*}{$\begin{array}{l}\text { MFPDI sub-scale scores: } \\
\text { mean (SD) }\end{array}$} & Functional limitation & $5.9(3.8)$ & $6.2(4.2)$ & $5.0(4.4)$ & **9.7 (5.8) \\
\hline & Pain & $5.1(2.0)$ & $4.8(2.4)$ & $3.6(2.5)$ & $* * 5.23(2.6)$ \\
\hline & Appearance & $3.6(1.5)$ & $1.0(1.2)$ & $0.9(1.2)$ & $* * 1.3(1.4)$ \\
\hline \multirow{2}{*}{$\begin{array}{l}\text { General Health } \\
\text { mean (SD) }\end{array}$} & SF 12 physical wellbeing & - & $41.8(6.8)$ & $46.9(2.4)$ & **47.5 (11.6) \\
\hline & SF 12 mental wellbeing & - & $30.8(9.7)$ & $33.8(4.6)$ & $* * 36.0(11.9)$ \\
\hline
\end{tabular}

-Data was not assessed or not applicable at this point in time.

*Significant difference $p<0.001$ Chi square test comparing UK NOrStOP to NL TO.

**Significant difference $\mathrm{p}<0.001$ T-test comparing UK NOrStOP to NL T0.

***Significant difference $p<0.05$ T-test comparing UK NOrStOP to NL T0. 
Table 2 Results of measurement properties related to: validity

\begin{tabular}{|c|c|c|c|c|c|}
\hline $\begin{array}{l}\text { Measurement } \\
\text { property }\end{array}$ & Research question & Method & Dataset(s) & Results & Interpretation \\
\hline \multirow{12}{*}{$\begin{array}{l}\text { Structural validity } \\
\text { (Factor analysis) }\end{array}$} & \multirow{12}{*}{$\begin{array}{l}\text { Do the Dutch MFPDI and } \\
\text { the NorStOP MFPDI consist } \\
\text { of the same factor structure } \\
\text { (sub-scales) as the original? }\end{array}$} & ECA & NL TO & Factors found: & \multirow{4}{*}{$\begin{array}{l}\text { A slightly different factor } \\
\text { structure fitted better in } \\
\text { both data sets than the } \\
\text { previously reported factor } \\
\text { structure. }\end{array}$} \\
\hline & & \multirow[t]{11}{*}{ CFA } & $n=205$ & $\begin{array}{l}\text { Functional construct: } \\
1-9\end{array}$ & \\
\hline & & & UK NorStOP & $\begin{array}{l}\text { Pain construct: 10, } \\
14-17\end{array}$ & \\
\hline & & & $n=365$ & $\begin{array}{l}\text { Perception construct: } \\
11-13\end{array}$ & \\
\hline & & & & $\begin{array}{l}\text { Previously reported } \\
\text { factor structure: }\end{array}$ & $\begin{array}{l}\text { The previously reported } \\
\text { factor structure fitted }\end{array}$ \\
\hline & & & & RMSEA NL: 0.07 UK:0.05 & $\begin{array}{l}\text { acceptable in the UK } \\
\text { dataset, but not in the }\end{array}$ \\
\hline & & & & CFI NL: 0.94 UK: 0.98 & Dutch dataset. \\
\hline & & & & TLI NL: 0.93 UK: 0.98 & \\
\hline & & & & $\begin{array}{l}\text { Factor structure found } \\
\text { in this study: }\end{array}$ & \\
\hline & & & & RMSEA NL: 0.06 UK:0.04 & \\
\hline & & & & CFI NL: 0.96 UK: 0.99 & \\
\hline & & & & TLI NL: 0.96 UK: 0.99 & \\
\hline \multirow[t]{6}{*}{$\begin{array}{l}\text { Cross cultural } \\
\text { validity }\end{array}$} & \multirow{6}{*}{$\begin{array}{l}\text { Assuming a similar 'true value' } \\
\text { for foot related disability, does } \\
\text { the Dutch population has the } \\
\text { same probability of endorsing } \\
\text { a certain response option on } \\
\text { the items of the MFPDI as } \\
\text { compared to the UK population? }\end{array}$} & \multirow{6}{*}{$\begin{array}{l}\text { DIF analysis using } \\
\text { ordinal regression } \\
\text { analyses. }\end{array}$} & NL TO & $\begin{array}{l}\text { Foot function } \\
\text { sub-scales: no DIF. }\end{array}$ & \multirow{6}{*}{$\begin{array}{l}\text { Assuming a similar 'true } \\
\text { value' for foot related } \\
\text { disability, the Dutch } \\
\text { population has a higher } \\
\text { probability of endorsing } \\
\text { the response option "none } \\
\text { of the time'" or "on some } \\
\text { days" on item } 17 \text { as } \\
\text { compared to the UK } \\
\text { population }\end{array}$} \\
\hline & & & $n=205$ & Foot pain sub-scale: & \\
\hline & & & UK NorStOP & Item 17 has DIF; & \\
\hline & & & $n=365$ & $R^{2}=0.048$ & \\
\hline & & & & $\begin{array}{l}\text { Theta for transition } \\
\text { score } 0 \text { to 1: }\end{array}$ & \\
\hline & & & & $\begin{array}{l}\mathrm{NL}=-1.38 \\
\mathrm{UK}=-0.29\end{array}$ & \\
\hline \multirow{10}{*}{$\begin{array}{l}\text { Construct validity } \\
\text { (hypotheses testing) }\end{array}$} & \multirow{10}{*}{$\begin{array}{l}\text { Does the MFPDI relate to other } \\
\text { instruments as expected, based } \\
\text { on the study of Garrow et al. [7] }\end{array}$} & Pearsson Correlation* & Comparator & Pearsson Correlations: & \multirow{10}{*}{$\begin{array}{l}\text { Construct validity is } \\
\text { accepted; all hypotheses } \\
\text { were confirmed. }\end{array}$} \\
\hline & & $\begin{array}{l}\text { Testing } 7 \text { a priori } \\
\text { defined hypotheses: }\end{array}$ & & & \\
\hline & & $\begin{array}{l}\text { 1. Correlation MFPDI-f } \\
\text { and FFI-f }(R>0.5) \text {. }\end{array}$ & NL TO & 1. R $0.66(p<0.000)^{*}$ & \\
\hline & & $\begin{array}{l}\text { 2. Correlation MFPDI-f } \\
\text { and SF12-phys } \\
(R>0.3) \text {. }\end{array}$ & $n=205$ & 2. $R 0.31(p<0.000)^{*}$ & \\
\hline & & $\begin{array}{l}\text { 3. R hypotheses } 1>R \\
\text { hypotheses } 2\end{array}$ & & 3. $R 0.66>0.0 .31^{*}$ & \\
\hline & & $\begin{array}{l}\text { 4. Correlation MFPDI-p } \\
\text { and FFI- } p(R>0.5)\end{array}$ & & 4. R $0.60(p<0.000)^{*}$ & \\
\hline & & $\begin{array}{l}\text { 5. Correlation MFPDI-p } \\
\text { and pain NRS }(R>0.5)\end{array}$ & & 5. R $0.53(p<0.000)^{*}$ & \\
\hline & & $\begin{array}{l}\text { 6. R MFPDI-f - SF-12 } \\
\text { phys > R MFPDI-f - } \\
\text { SF12 ment }\end{array}$ & & $\begin{array}{l}\text { 6. } R 0.31>R 0.14 \\
(p=0.045)^{*}\end{array}$ & \\
\hline & & \multirow{2}{*}{$\begin{array}{l}\text { 7. R MFPDI-f - SF-12 } \\
\text { phys > R MFPDI-p - } \\
\text { SF-12 phys }\end{array}$} & & $\begin{array}{l}\text { 7. R } 0.31>R 0.22 \\
(p=0.002)^{*}\end{array}$ & \\
\hline & & & & $\begin{array}{l}{ }^{*} \text { A priori defined } \\
\text { hypothesis confirmed }\end{array}$ & \\
\hline
\end{tabular}


Table 3 Results of measurement properties related to: reliability

\begin{tabular}{|c|c|c|c|c|c|}
\hline $\begin{array}{l}\text { Measurement } \\
\text { property }\end{array}$ & Research question & Method & Dataset(s) & Results & Interpretation \\
\hline \multirow[t]{3}{*}{ Internal consistency } & \multirow{3}{*}{$\begin{array}{l}\text { Do the items within the } \\
\text { (uni-dimensional) sub-scales } \\
\text { correlate highly? }\end{array}$} & \multirow{3}{*}{$\begin{array}{l}\text { Cronbach's a } \\
\text { (per sub-scale) }\end{array}$} & NL TO & Function: 0.84 & \multirow{3}{*}{$\begin{array}{l}\text { The foot function scale is internally } \\
\text { consistent }(>0.7) \text {. Internal consistency of } \\
\text { the other sub-scales is moderate. }\end{array}$} \\
\hline & & & $n=205$ & Pain: 0.67 & \\
\hline & & & & Perception: 0.61 & \\
\hline \multirow[t]{3}{*}{ Test-retest reliability } & \multirow{3}{*}{$\begin{array}{l}\text { Does the Dutch MFPDI } \\
\text { produce similar results when } \\
\text { completed repeatedly within } \\
\text { an interval of two weeks? }\end{array}$} & \multirow[t]{3}{*}{$\begin{array}{l}\text { ICC absolute agreement } \\
\text { (per sub-scale) }\end{array}$} & $\begin{array}{l}\text { NL Ts and } \\
\text { NL TO }\end{array}$ & Function: 0.69 & \multirow{3}{*}{$\begin{array}{l}\text { The test-retest reliability of the function } \\
\text { scale is nearly acceptable. Neither of the } \\
\text { other scales is reliable. }\end{array}$} \\
\hline & & & $n=195$ & Pain: 0.49 & \\
\hline & & & & Perception: 0.10 & \\
\hline \multirow[t]{3}{*}{$\begin{array}{l}\text { Measurement error } \\
\text { (agreement) }\end{array}$} & \multirow[t]{3}{*}{$\begin{array}{l}\text { Which part of the variance is } \\
\text { due to measurement error? }\end{array}$} & \multirow[t]{3}{*}{ SEM (per sub-scale) } & $\begin{array}{l}\text { NL Ts and } \\
\text { NL TO }\end{array}$ & Function: 2.2 & \multirow{3}{*}{$\begin{array}{l}\text { There are no set guidelines of what is } \\
\text { acceptable for the magnitude of SEM. } \\
\text { Function scale SEM of total score is: } \\
12 \% \text {, pain scale: } 16 \% \text {, perception: } 36 \%\end{array}$} \\
\hline & & & \multirow[t]{2}{*}{$n=195$} & Pain: 1.6 & \\
\hline & & & & Perception: 2.1 & \\
\hline
\end{tabular}

answering this item with: "none of the time" or "on some days" than the UK population.

\section{Responsiveness}

One of the 7 a priori stated hypotheses about correlations between different change scores (change score = the difference between the scale score at NL T0 and NL T3) was confirmed (Table 4). Neither the function scale nor the pain scale change scores correlated to the corresponding GPE questions at an acceptable level (respectively $\mathrm{R}=0.46$ and $\mathrm{R}=0.47$ ). These correlations were considered too low to calculate a MIC.

\section{Interpretability}

The perception sub-scale showed an extreme floor effect; $86.2 \%$ of the participants obtained the minimum possible scale score. The other sub-scales do not exhibit a floor or ceiling effect (Table 4).

The SDC of the perception sub-scale is as large as the maximum obtainable score of 6 points (Table 4). Due to the inability to calculate a MIC, comparison of SDC and MIC is not possible.

\section{Discussion}

Evaluation of the MFPDI measurement properties produced new useful information. Of the 3 uni-dimensional sub-scales found in the NL T0 data only the functional limitation sub-scale has an acceptable level of reliability. Scores from the Dutch and UK version can be interpreted similarly; only the pain subscale possesses one DIF item but the differences in item responses and thus sub-scale responses are smaller than the measurement error. The responsiveness of the questionnaire is moderate.

Several studies have investigated the presence of subscales within the MFPDI using either EFA and/or CFA. Although differences have been found in the number of sub-scales: 2 [8], 3 [12] or 4 [7,10]; close inspection shows several similarities between the different outcomes. The main difference between the various factor structures is the placement of item 11 ("I get irritable when my feet hurt."). Previous analyses have placed this item in the foot function scale $[7,12]$, in the foot pain scale [10] and in a combined pain and appearance scale [8]. In our opinion item 11 is related to emotion due to foot pain and therefore should not be part of the foot function scale. In our data it fits best with items 12 and 13 which were previously labelled as appearance items. These two items are actually about feeling self-conscious about the appearance of feet and shoes and do not mention the appearance itself of feet and shoes. Adding item 11 to these two and naming it "perception scale" adds to the face-validity of the scale in our opinion.

\section{Reliability}

Although internal consistency has been evaluated in every MFPDI validation study published [7-12], only two studies evaluated the IC per individual sub-scale $[8,12]$. Both studies found acceptable internal consistencies $(>0.7)$ for all tested sub-scales in contrast to our findings. Our findings suggest that the functional scale is internally consistent (0.84), the pain scale is just below acceptable (0.67) and the internal consistency of the perception sub-scale is moderate (0.60). The differences between our results and those found by Cook et al. [8] (IC of the pain and appearance scale: 0.75 ) could be explained by the differences in the number of items; respectively 3 and 7 items. The test-retest reliability of the foot function sub-scale is almost acceptable $(\mathrm{ICC}=0.69)$ but the reliability of the pain sub-scale is moderate (0.49) and the reliability of the perception sub-scale is poor (0.10). All participants scored at least one item of the entire MFPDI as: "on most/every day(s)" and our findings are consistent with those reported by Roddy et al. [12]. A measurement error has not been established before. Our findings suggest that the SEM for the perception scale is too large; $36 \%$ of the possible maximum score. 
Table 4 Results of measurement properties related to: responsiveness and interpretability

\begin{tabular}{|c|c|c|c|c|c|}
\hline $\begin{array}{l}\text { Measurement } \\
\text { property }\end{array}$ & Research question & Method & Dataset(s) & Results & Interpretation \\
\hline \multirow[t]{10}{*}{ Responsiveness } & \multirow{10}{*}{$\begin{array}{l}\text { Do change scores on } \\
\text { the MFPDI relate to } \\
\text { change scores on } \\
\text { other instruments as } \\
\text { expected? }\end{array}$} & Pearsson Correlation* & \multirow{2}{*}{\multicolumn{2}{|c|}{$\begin{array}{l}\text { Comparator instruments: } \\
\text { FFI, NRS, SF12phys, } \\
\text { GPEpain and GPEfunction }\end{array}$}} & \multirow{10}{*}{$\begin{array}{l}\text { The responsiveness of the } \\
\text { MFPDI is moderate; only } 1 \text { out } \\
\text { of } 7 \text { hypotheses was confirmed } \\
\text { and the correlation with the } \\
\text { GPE question is }<0.2 \text {. }\end{array}$} \\
\hline & & $\begin{array}{l}\text { Testing } 7 \text { a priori } \\
\text { defined hypotheses: }\end{array}$ & & & \\
\hline & & $\begin{array}{l}\text { 1. Correlation change } \\
\text { MFPDI-f and FFI-f } \\
(R>0.5)\end{array}$ & $\begin{array}{l}\text { T0 and measurement } \\
\text { after } 3 \text { months (NL T3) }\end{array}$ & 1. R $0.31(p<0.000)$ & \\
\hline & & $\begin{array}{l}\text { 2. Correlation change } \\
\text { MFPDI- } f \text { and SF12 } \\
\text { phys }(R>0.5)\end{array}$ & \multirow[t]{7}{*}{$n=178$} & 2. $R 0.03(p=0.747)$ & \\
\hline & & $\begin{array}{l}\text { 3. Correlation change } \\
\text { MFPDI-f and GPE-f } \\
(R>0.5)\end{array}$ & & 3. $R-0.46(p<0.000)$ & \\
\hline & & $\begin{array}{l}\text { 4. R hypothesis } 1>R \\
\text { hypothesis } 2 \text {. }\end{array}$ & & 4. R $0.31>$ R $0.03^{*}$ & \\
\hline & & $\begin{array}{l}\text { 5. Correlation change } \\
\text { MFPDI-p and FFI-p } \\
(R>0.5)\end{array}$ & & 5. R $0.37(p<0.000)$ & \\
\hline & & $\begin{array}{l}\text { 6. Correlation change } \\
\text { MFPDI-p and pain } \\
\text { NRS }(R>0.5)\end{array}$ & & 6. R $0.42(p<0.000)$ & \\
\hline & & \multirow{2}{*}{$\begin{array}{l}\text { 7. Correlation change } \\
\text { MFPDI-p and GPE-p } \\
(R>0.5)\end{array}$} & & 7. $R-0.47(p<0.000)$ & \\
\hline & & & & $\begin{array}{l}{ }^{*} A \text { priori defined } \\
\text { hypothesis }\end{array}$ & \\
\hline \multirow[t]{11}{*}{ Interpretability } & \multirow{3}{*}{$\begin{array}{l}\text { What is the Minimal } \\
\text { Important change } \\
\text { (MIC)? }\end{array}$} & \multirow{2}{*}{$\begin{array}{l}\text { MIC: smallest cut-off } \\
\text { change score } \\
\text { (1-sensitivity)+ }\end{array}$} & MIC: NL TO, & \multirow{3}{*}{$\begin{array}{l}\text { The correlation } \\
\text { coefficient between } \\
\text { the GPE and change } \\
\text { score is too low } \\
\text { to calculate a MIC } \\
(R<0.5) \text {. }\end{array}$} & \multirow{3}{*}{$\begin{array}{l}\text { The MFPDI is not responsive } \\
\text { enough to calculate a MIC. }\end{array}$} \\
\hline & & & NL T3 & & \\
\hline & & (1-specificity) & $n=178$ & & \\
\hline & \multirow{4}{*}{$\begin{array}{l}\text { What is the Smallest } \\
\text { Detectable Change } \\
\text { (SDC)? And is the } \\
\text { MIC higher than the } \\
\text { SDC? }\end{array}$} & \multirow[t]{4}{*}{ SDC } & \multirow[t]{4}{*}{ SDC: NL TO $n=205$} & SDC: & \multirow{4}{*}{$\begin{array}{l}\text { The SDC for the perception } \\
\text { sub-scale is too large; the SDC } \\
\text { is equal to the maximum } \\
\text { possible score. }\end{array}$} \\
\hline & & & & $\begin{array}{l}\text { Function: } 6.1 \text { (min-max } \\
\text { score: 0-18) }\end{array}$ & \\
\hline & & & & Pain: 4.4 (0-10) & \\
\hline & & & & Perception: 5.8 (0-6) & \\
\hline & \multirow{4}{*}{$\begin{array}{l}\text { Is a floor and or } \\
\text { ceiling effect } \\
\text { present? }\end{array}$} & \multirow{4}{*}{$\begin{array}{l}\text { Floor/ceiling effect: } \% \\
\text { of participants who } \\
\text { scored the two lowest } \\
\text { possible scores ( } 0 \text { or } 1 \text { ) } \\
\text { per sub-scale. }\end{array}$} & \multirow{4}{*}{$\begin{array}{l}\text { Floor/ceiling effect: NL T0 } \\
n=205\end{array}$} & Floor/ceiling effects: & \multirow{4}{*}{$\begin{array}{l}\text { The perception sub-scale } \\
\text { exhibits a large floor effect. }\end{array}$} \\
\hline & & & & Function: $8.8 \%$ & \\
\hline & & & & Pain: $7.4 \%$ & \\
\hline & & & & Perception: 76.5\% & \\
\hline
\end{tabular}

${ }^{*}$ MFPDI-f $=$ MFPDI- function items, FFI- $f=$ FFI- 5 pts function items, SF-12 phys $=$ SF12 physical function items, GPE-f $=$ GPE-function question, MFPDI- $p=$ MFPDI- pain items, FFI- $p=$ FFI- 5 pts pain items, NRS- $p=$ Pain Numeric Rating Scale, GPE- $p=$ GPE-pain.

\section{Validity}

The UK and Dutch participants differ on baseline on the amount of foot related pain and dysfunction. However, these differences are not of influence on the crosscultural validity analyses because item responses of UK and Dutch patients with similar 'true values' are compared to each other.

Assessment of the cross cultural validity by means of DIF analysis showed that Dutch and UK participants with a similar level of foot dysfunction complete the foot function sub-scale in a similar manner. A small difference was found in the completion of the foot pain sub- scale. Assuming a similar 'true value' for foot related disability, the Dutch population has a higher probability of endorsing the response option "none of the time"" or "on some days" on item 17 as compared to the UK population. We expect that the DIF of item 17 is due to the difference in location of the foot pain. The UK population was included if they had pain in any part of the foot whereas the Dutch population was selected when having pain in the forefoot or toes. It is plausible that the characteristics of forefoot pain might differ from the characteristics of general foot pain explaining the difference between the Dutch and UK population. 
The seven a priori stated hypotheses were all confirmed and thus the foot function and the pain scales seem to be valid. Due to absence of a comparator instruments the validity of the perception scale has not been assessed. In a previous study by Menz et al. [10] the MFPDI scores were compared to other patient reported outcomes like the GADS depression sub-scale and the SF-36 mental health and general health sub-scale. These correlation coefficients were lower than those in our results; their highest correlation was $R=0.34$. This is probably due to the fact that the comparator instruments differ in both studies and that the instruments used in this study are more foot related. Even though the construct validity is acceptable based on these findings, we are hesitant about the face validity of the foot pain scale. Previous authors have described this scale as measuring pain intensity $[7,11,12]$. Examining the items in this scale it is striking that none of the items actually posses a reference to pain intensity. The items mainly ask about when the foot pain is worse and about the kind of pain. This scale also contains several opposing statements. Item 15 states: "My feet are worse in the morning" whilst item 16 states: "My feet are more painful in the evening". Items 14 and 17 are somewhat opposing as well: "I have constant pain in my feet" versus I have shooting pain in my feet". We are hesitant to use this sub-scale if pain intensity is the construct of interest.

\section{Responsiveness and interpretation}

Neither responsiveness nor a MIC have previously been established. Comparing the change scores of the foot function and the pain sub-scale to changes in comparator instruments like the foot function index-5 pt (foot related activities and pain sub-scales), the SF12 physical component and the pain NRS, only moderate correlations were found. But most importantly, the correlation between the change scores and anchor question (GPE question) were only moderate $(R=0.43-0.47)$. We considered these correlation coefficients too low (below 0.5 ) to calculate a MIC. There are multiple possible explanations for the moderate responsiveness. With regard to the entire questionnaire, it could be that the response options (none of the time, on some days and on most/ every day(s)) are too widely spaced to be able to measure small changes over time. With regard to the foot function sub-scale; the questionnaire uses items that clearly begin with: 'because of the pain in my feet...'. Even so, the activities stated could very likely be influenced by other variables like loss of muscle strength or pain in other joints, especially within an older population. It could possibly be hard to distinguish the inability to do something because of foot pain or other pains and therefore it might not respond to change if only one of the problems improves. The SDC is calculated based on the SEM and so the perception scale has an extreme high SDC; 5.8 points on a scale that has a 6 point maximum. This sub-scale also has a large floor effect; $76.5 \%$ of the participants have a score of 0 or 1 point. Combining these two findings, it will be improbable to find a change within this scale.

The main strength of this study is that the full array of measurement properties based on CTT has been evaluated. Nevertheless, the results of this study should be interpreted in light of its limitations. The group of participants used for this evaluation of the MFPDI (NL T0) is very homogeneous; $>50$ years of age, visited their GP with forefoot pain not due to rheumatoid arthritis or skin lesions and no diabetic neuropathy. Particularly the attribute of having forefoot pain is different compared to other studies. Even though our results do not seem to differ a lot from previously published work, measurement properties like responsiveness, MIC, SDC and SEM have not been assessed before. And thus it is unsure if, for instance, the moderate responsiveness the MFPDI holds for populations with other kinds of foot pain as well. Another limitation is that the power in this study was insufficient to assess DIF for variables like to age, gender and location of foot pain.

Although foot pain in general is more common in woman than in man [2,3]. The percentage of women in this study $(77.6 \%)$ differ from both gender distributions reported by Garrow et al. [2] (59.6\%) or the UK NOrStOP data (63\%). These studies contain people with foot pain in general. It could be that women are, more so than men, predisposed to have forefoot problems, compared to pain anywhere in the foot. Nevertheless, most outcomes in this study are comparable to those of other studies [9-12]. We therefore assume that the difference in gender distribution does not affect the outcome of this study.

\section{Conclusion}

Results using the Dutch version of the MFPDI are not different from those using the English version since the function scale has no DIF and the pain scale only a small amount. Due to the limited reliability, moderate responsiveness, floor effect and large measurement error of both the pain and most of all the perception scale, found in our study and other studies it is advisable that the items in these scales (item 1017) are used with extreme caution. Quantifying pain by the use of a NRS or VAS can be an alternative. The reliability of the function scale (items 1-9) is acceptable as is its construct validity. The moderate responsiveness of the MFPDI function scale should be taken into consideration when using it in a longitudinal study. It is unclear if these results would be 
different for participants with foot pain other than the forefoot or if the results are influenced by problems in the entire lower extremity.

\section{Abbreviations}

CFA: Confirmatory factor analysis; CTT: Classical Test Theory; DIF: Differential item functioning; EFA: Exploratory factor analysis; FFI: Foot function index; GPE: Global perceived effect (also known as anchor question); IC: Internal consistency; ICC: Intraclass correlation; IRT: Item response theory; MFPDI: Manchester Foot Pain and Disability Index; MIC: Minimal important change; NL TS: T0, T3, Dutch datasets respectively just prior to baseline, baseline and after 3 months; NRS: Numeric rating scale; SEM: Standard error of measurement; SDC: Smallest detectable change.

\section{Competing interests}

The authors declare that they have no competing interests.

\section{Authors' contributions}

BvdZ was responsible for data-collection and wrote the manuscript. CT assisted with the statistical analysis, BT assisted with the DIF analysis. PE commented on several drafts of the manuscript. CT, ER, BT and HH commented on the first and last draft of the manuscript. All authors have read and approved the final manuscript.

\section{Acknowledgements}

This study is funded by the Netherlands Organisation for Health Research and Development (ZonMw: 42011003). Secondly, the authors acknowledge the assistance of Isis Outcomes (Isis Innovation Ltd, Oxford UK) for granting permission to use the MFPDI in this study. Permissions to use the MFPDI in all translations can be sought directly from Isis Outcomes (http://isisinnovation.com/outcomes/index.html).

\section{Author details}

${ }^{1} \mathrm{EMGO}+$ Institute for health and care research, Department of general practice and elderly care medicine, VU University Medical Centre,

Amsterdam, The Netherlands. ${ }^{2} \mathrm{EMGO}+$ Institute for health and care research, Department of Epidemiology and Biostatistics, VU University Medical Centre, Amsterdam, The Netherlands. ${ }^{3}$ Research Institute for Primary Care and Health Sciences, Keele University, Staffordshire, UK.

Received: 16 May 2013 Accepted: 17 July 2014

Published: 12 August 2014

\section{References}

1. Benvenuti F, Ferrucci L, Guralnik JM, Gangemi S, Baroni A: Foot pain and disability in older persons: an epidemiologic survey. J Am Geriatr Soc 1995, 43:479-484.

2. Garrow AP, Silman AJ, Macfarlane GJ: The Cheshire foot pain and disability survey: a population survey assessing prevalence and associations. Pain 2004, 110:378-384.

3. Gorter KJ, Kuyvenhoven MM, de Melker RA: Nontraumatic foot complaints in older people: a population-based survey of risk factors, mobility, and well-being. J Am Podiatr Med Assoc 2000, 90:397-402.

4. Menz HB, Gill TK, Taylor AW, Hill CL: Age and gender differences in disabling foot pain using different definitions of the Manchester foot pain and disability index. BMC Musculoskelet Disord 2011, 12:243.

5. Picavet HSJ, Schouten JSAG: Musculoskeletal pain in the Netherlands: prevalences, consequences and risk groups, the DMC(3)-study. Pain 2003, 102:167-178.

6. van der Windt DAWM, Dunn KM, Spies-Dorgelo MN, Mallen CD, Blankenstein AH, Stalman WAB: Impact of physical symptoms on perceived health in the community. J Psychosom Res 2008, 64:265-274.

7. Garrow AP, Papageorgiou AC, Silman AJ, Thomas E, Jayson MI, Macfarlane GJ: Development and validation of a questionnaire to assess disabling foot pain. Pain 2000, 85:107-113.

8. Cook CE, Cleland J, Pietrobon R, Garrow AP, Macfarlane GJ: Calibration of an item pool for assessing the disability associated with foot pain: an application of item response theory to the Manchester foot pain and disability index. Physiotherapy 2007, 93:89-95.
9. Kaoulla P, Frescos N, Menz HB: Development and validation of a Greek language version of the Manchester foot pain and disability index. Health Qual Life Outcomes 2008, 6:39.

10. Menz HB, Tiedemann A, Kwan MMS, Plumb K, Lord SR: Foot pain in community-dwelling older people: an evaluation of the Manchester foot pain and disability index. Rheumatology (Oxford) 2006, 45:863-867.

11. Muller S, Roddy E: A rasch analysis of the Manchester foot pain and disability index. J Foot Ankle Res 2009, 2:29.

12. Roddy E, Muller S, Thomas E: Defining disabling foot pain in older adults: further examination of the Manchester foot pain and disability index. Rheumatology (Oxford) 2009, 48:992-996.

13. Bowen CJ, Edwards CJ, Hooper L, Dewbury K, Sampson M, Sawyer S, Burridge J, Arden NK: Improvement in symptoms and signs in the forefoot of patients with rheumatoid arthritis treated with anti-TNF therapy. J Foot Ankle Res 2010, 3:10.

14. de Morais BC, Barros Bertolo M, Marques Neto JF, Bellini Coimbra I, Davitt M, de Paiva ME: The effect of foot orthoses on balance, foot pain and disability in elderly women with osteoporosis: a randomized clinical trial. Rheumatology (Oxford) 2013, 52:515-522.

15. van der Zwaard BC, Elders PJ, Knol DL, Gorter KJ, Peeraer L, van der Windt DA, van der Horst HE: Treatment of forefoot problems in older people: study protocol for a randomised clinical trial comparing podiatric treatment to standardised shoe advice. J Foot Ankle Res 2011, 4:11.

16. Beaton DE, Bombardier C, Guillemin F, Ferraz MB: Guidelines for the process of cross-cultural adaptation of self-report measures. Spine (Phila Pa 1976) 2000, 25:3186-3191.

17. Mokkink LB, Terwee CB, Knol DL, Stratford PW, Alonso J, Patrick DL, Bouter $L M$, de Vet HC: The COSMIN checklist for evaluating the methodological quality of studies on measurement properties: a clarification of its content. BMC Med Res Methodol 2010, 10:22.

18. Mokkink LB, Terwee CB, Patrick DL, Alonso J, Stratford PW, Knol DL, Bouter $L M$, de Vet HC: The COSMIN checklist for assessing the methodological quality of studies on measurement properties of health status measurement instruments: an international Delphi study. Qual Life Res 2010, 19:539-549.

19. Kuyvenhoven MM, Gorter K, Zuithoff P, Budiman-Mak E, Conrad KJ, Post MWM: The foot function index with verbal rating scales (FFl-5pt): a clinimetric evaluation and comparison with the original FFI. J Rheumatol 2002, 29:1023-1028

20. Thomas E, Wilkie R, Peat G, Hill S, Dziedzic K, Croft P: The North Staffordshire Osteoarthritis Project-NorStOP: prospective, 3-year study of the epidemiology and management of clinical osteoarthritis in a general population of older adults. BMC Musculoskelet Disord 2004, 5:2.

21. Peat G, Thomas E, Handy J, Wood L, Dziedzic K, Myers H, Wilkie R, Duncan R, Hay E, Hill J, Lacey R, Croft P: The Knee Clinical Assessment Study-CAS (K): a prospective study of knee pain and knee osteoarthritis in the general population: baseline recruitment and retention at 18 months. BMC Musculoskelet Disord 2006, 7:30.

22. Menz HB, Jordan KP, Roddy E, Croft PR: Musculoskeletal foot problems in primary care: what influences older people to consult? Rheumatology (Oxford) 2010, 49:2109-2116.

23. Hu LT, Bentler PM: Cut-off criteria for fit indexes in covariance structure analysis: conventional criteria versus new alternatives. Struct Equ Model 1999, 6:1-55.

24. Schreiber JB, Nora A, Stage FK, Barlow EA, King J: Reporting structural equation modeling and confirmatory factor analysis results: a review. J Educ Res 2006, 99:323-337.

25. Terwee CB, Bot SDM, de Boer MR, van der Windt DAWM, Knol DL, Dekker J, Bouter LM, de Vet HC: Quality criteria were proposed for measurement properties of health status questionnaires. J Clin Epidemiol 2007, 60:34-42.

26. de Vet HCW, Terwee CB, Knol DL, Bouter LM: When to use agreement versus reliability measures. J Clin Epidemiol 2006, 59:1033-1039.

27. De Vet HCW, Terwee CB, Mokkingk LB, Knol DL: Measurement in Medicine. 1st edition. Cambridge: Cambridge University Press; 2011.

28. Choi SW, Gibbons LE, Crane PK: Lordif: an (R) package for detecting differential item functioning using iterative hyprid ordinal logistic regression/item response theory and monte carlo simulations. J Stat Softw 2011, 39:1-30.

29. Petersen MA, Groenvold M, Bjorner JB, Aaronson N, Conroy T, Cull A, Fayers P, Hjermstad M, Sprangers M, Sullivan M, European Organisation for Research and Treatment of Cancer: Use of differential item functioning 
analysis to assess the equivalence of translations of a questionnaire. Qual Life Res 2003, 12:373-385.

30. de Vet HCW, Ostelo RWJG, Terwee CB, van der Roer N, Knol DL, Beckerman $H$, Boers M, Bouter LM: Minimally important change determined by a visual method integrating an anchor-based and a distribution-based approach. Qual Life Res 2007, 16:131-142.

doi:10.1186/1471-2474-15-276

Cite this article as: van der Zwaard et al:: Evaluation of the measurement properties of the Manchester foot pain and disability index. BMC

Musculoskeletal Disorders 2014 15:276.

\section{Submit your next manuscript to BioMed Central and take full advantage of:}

- Convenient online submission

- Thorough peer review

- No space constraints or color figure charges

- Immediate publication on acceptance

- Inclusion in PubMed, CAS, Scopus and Google Scholar

- Research which is freely available for redistribution 